\title{
Perancangan Aplikasi Sistem Pakar Konsultasi Psikologis Anak Berbasis Web
}

\author{
Hamdhany Abdhi Kurnia ${ }^{1}$, Yuni Widiastiwi ${ }^{2}$, Ati Zaidiah ${ }^{3}$ \\ Informatika / Fakultas Ilmu Komputer \\ Universitas Pembangunan Nasional Veteran Jakarta \\ Jl. Rs. Fatmawati, Pondok Labu, Jakarta Selatan, DKI Jakarta, 12450, Indonesia \\ email: hamdhanykurnia@gmail.com¹, widiastiwi@yahoo.com², zaidiah21@gmail.com³
}

\begin{abstract}
Abstrak. Sistem pakar psikologis ini dibuat bertujuan agar orang tua menyadari bahwa kesehatan psikologis sangat berpengaruh penting untuk tumbuh kemabang anak, karena akan berpengaruh terhadap mental dan pola piker sang anak. Sistem pakar ini dibuat menggunakan metode algoritma forward chaining yang berfungsi sebagai penghasil kesimpulan dari data-data yang sudah didapatkan melalui pakar. Untuk mendapatkan hasil, sistem pakar memproses data-data gejala yang dialami oleh anak yang telah dipilih melalui menu konsultasi pada sistem pakar. Yang dihasilkan dari penelitian ini berupa sistem pakar berbasis website yang dapat membantu orang tua untuk mengetahui apakah anak mereka memiliki gangguan kesehatan psikologis dan memberikan solusi awal untuk menangani gangguan yang dialami.
\end{abstract}

Kata Kunci: Sistem pakar, Psikologi anak, Forward chaining, Web

\section{Pendahuluan}

Psikologi adalah ilmu yang mempelajari tentang perilaku. Dimana yang dipelajari adalah semua perilaku yang ditunjukkan oleh manusia yang bisa dijelaskan oleh ilmu psikologi tersebut. Jika seseorang menunjukan perilaku tertentu, maka ilmu psikologi lah yang tepat untuk menjelaskan hal tersebut. Psikologi memiliki arti yaitu ilmu yang memperlajari tentang pikiran dari seorang manusia yang nantinya akan berkembang menjadi prilaku dari orang tersebut [1].

Psikologi seorang anak sangatlah menentukan tumbuh kembangnya nanti. Dengan demikian, dibutuhkanlah sebuah perhatian yang lebih khusus terhadap bagaimana perkembangan psikologisnya sehingga seorang anak akan memiliki perilaku yang baik terhadap keluarga dan lingkungan sekitarnya.

Sebagai orang tua yang memiliki peran sangat penting untuk memberikan contoh-contoh perilaku yang baik terhadap anaknya dan mengawasi bagaimana perkembangan yang terjadi harus meluangkan waktu lebih banyak untuk berkomunikasi dengan anak mereka. Hal ini sangat penting dilakukan oleh orang tua untuk menjadi pendamping seorang anak yang dimana seorang anak selalu menjadikan orang tua sebagai panutan mereka. Jika waktu berkomunikasi seorang anak dengan orang tua mereka kurang, maka anak akan merasa kurang diperhatikan sehingga mereka akan mencari role model yang menurut mereka dekat dengan kehidupannya yang akan mereka contoh.

Dengan perkembangan teknologi informasi yang sangat pesat saat ini akan dibutuhkannya sebuah sistem pakar yang mengidentifikasi kesehatan psikologis seorang anak apakah itu baik ataupun buruk. Sistem ini mampu membantu memberikan alternatif pengambilan keputusan yang memiliki tingkat performa sebanding dengan seorang psikolog. Dengan mengetahui apa saja yang menjadikan psikologis seorang anak itu baik/sehat akan bisa dicontoh oleh orang tua yang lain dan sebaliknya jika psikologis anak tersebut dinilai buruk/tidak sehat, sistem akan memberikan sebuah sebuah saran. Dengan diberikannya saran oleh sistem, diharapkan orang tua dapat melakukan pencegahan terhadap perkembangan yang bisa terjadi dan menjadi pencegahan awal agar tidak terjadinya gangguan psikologis. 


\section{Metodologi Penelitian}

\subsection{Sistem Pakar}

Secara umum, sistem yang kinerjanya mampu meniru keahlian seorang pakar pada bidang tertentu dan disajikan dengan tampilan yang bisa digunakan oleh pengguna untuk mendapatkan sebuah keputusan yang sesuai dengan kebijakan seorang pakar disebut sistem pakar [2]. Sistem pakar adalah program komputer yang berbasiskan data pengetahuan seorang ahli nantinya data tersebut dimasukkan kedalam sistem, agar komputer bisa memecahkan masalah seperti seorang ahli. Sistem akan berfokus pada penyelesaian masalah layaknya seorang pakar [3].

\subsection{Forward Chaining}

Forward chaining merupakan suatu penalaran yang dimulai dari fakta untuk mendapatkan kesimpulan (conclusion) dari fakta tersebut [4].Metode ini mencari kesimpulan berdasarkan data fakta yang sudah dikaji yang bergerak mengarah kedepan agar mampu menemukan pemecahan masalah atau solusi yang tepat. Bisa dilihat pada gambar berikut.

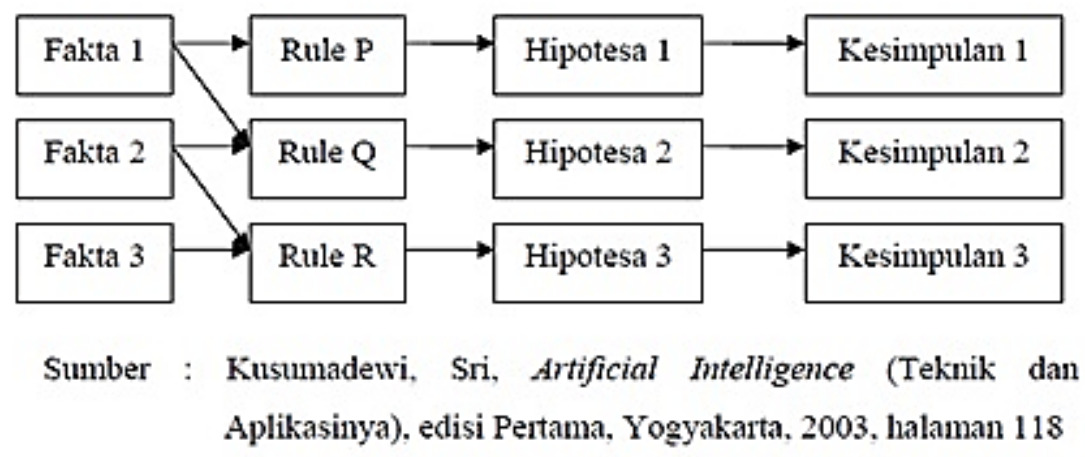

Gambar 1. Algoritma Forward Chaining

\subsection{Metode Penelitian}

Pada metodologi penelitian ini, tahapan penelitian disajikan dalam bentuk flowchart dibawah ini:

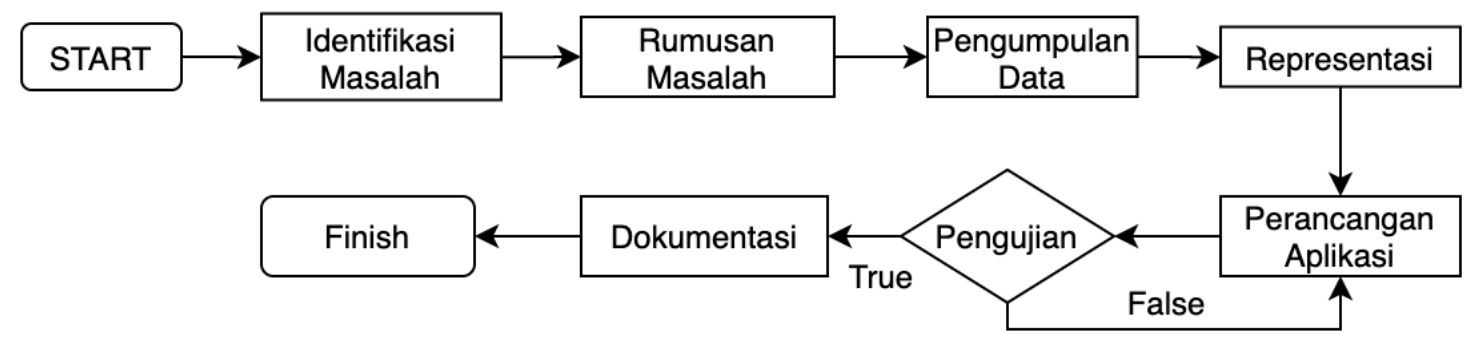

Gambar. 2. Flowchart metodologi penelitian yang diaplikasikan. 
Uraian proses tahapan penelitian pada gambar 2 adalah sebagai berikut:

a. Identifikasi Masalah, pada tahap ini penulis akan menyusun permasalahan apa saja yang terdapat pada identifikasi masalah agar mendapatkan rumusan masalah mengenai sistem pakar berbasis aplikasi agar pengguna mendapatkan hasil yang akurat.

b. Pengumpulan Data, tahapan pertama adalah pengumpulan data dan informasi yang dimana penulis mewawancarai seorang pakar psikologis dan jurnal-jurnal mengenai psikologis dan motorik untuk mendapatkan data-data yang dibutuhkan.

c. Representasi, dengan metode ini, penulis memanfaatkan data-data yang sudah didapatkan untuk melakukan pengkodean pengetahuan dalam sistem pakar untuk mendapatkan solusi dari permasalahan.

d. Perancangan Sistem, tahap ini akan dilakukan perancangan sistem agar memiliki gambaran bagaimana nantinya sistem akan bekerja dengan pemodelan UML.

e. Pengujian, pada tahap ini penulis akan melakakukan pengujian sistem pakar yang sudah dibuat, apakah setiap тепu bekerja dengan baik dan sistem menghasilkan akurasi yang tepat.

f. Dokumentasi, tahapan pertama adalah pengumpulan data dan informasi yang dimana penulis akan mewawancarai seorang pakar psikologis dan jurnal-jurnal mengenai psikologis dan motorik untuk mendapatkan data-data yang dibutuhkan.

\section{Hasil dan Pembahasan}

\subsection{Pengumpulan Data}

Setelah mendapatkan data-data yang dibutuhkan melalui wawancara dengan pakar yaitu dr. I Nyoman Budastra, Sp.A [6] maka data tersebut dimanfaatkan untuk diproses oleh sistem untuk dijadikan sebuah aturan. Aturan tersebut nantinya digunakan untuk mencocokkan gejala apa yang dirasakan dan menghasilkan sebuah pendeteksian dan pengendalian penyakit.

Tabel 1. Data penyakit

\begin{tabular}{cl} 
No & Penyakit \\
\hline $\mathbf{1}$ & Anxiety disorder \\
\hline $\mathbf{2}$ & Psychotic disorder \\
\hline $\mathbf{3}$ & Impulse control and addition disorders \\
\hline $\mathbf{4}$ & Ptsd \\
\hline $\mathbf{5}$ & Psychopath \\
\hline $\mathbf{6}$ & Autisme \\
\hline $\mathbf{7}$ & Retardasi mental \\
\hline $\mathbf{8}$ & Disleksia \\
\hline $\mathbf{9}$ & Adhd \\
\hline $\mathbf{1 0}$ & Disosiatif
\end{tabular}

Tabel 1 diatas merupakan data penyakit psikologi yang memungkinkan diderita oleh anak-anak didapatkan dari hasil wawancara dengan pakar. 
Tabel 2. Data gejala dan faktor penyebab.

\begin{tabular}{|c|c|c|c|}
\hline No & Gejala & Faktor-Faktor & Penyakit \\
\hline 1 & $\begin{array}{l}\text { Apakah ketika sedang berbicara sering } \\
\text { melantur atau tidak sesuai topik pembicaraan? }\end{array}$ & Sering dikucilkan terhadap teman-temannya & Anxiety disorder \\
\hline 2 & $\begin{array}{l}\text { Apakah memiliki suatu peristiwa yang } \\
\text { traumatis? }\end{array}$ & $\begin{array}{l}\text { Adanya masalah internal yang tidak dapat } \\
\text { diungkapkan oleh anak }\end{array}$ & Psychotic disorder \\
\hline 3 & Apakah merasa gugup dan gelisah? & $\begin{array}{l}\text { Karena memiliki pikiran yang membuatnya } \\
\text { stress atau menganggunya }\end{array}$ & $\begin{array}{l}\text { Impulse control and } \\
\text { addition disorders }\end{array}$ \\
\hline 4 & Apakah sering berhalusinasi? & Pola tidur yang diterapkan tidak teratur & Ptsd \\
\hline 5 & Apakah sering delusinasi? & $\begin{array}{l}\text { Anak merasa tidak memiliki suatu } \\
\text { kelebihan yang menonjol untuk ditunjukkan }\end{array}$ & Psychopath \\
\hline 6 & Apakah sulit berkonsentrasi di keramaian? & $\begin{array}{l}\text { Anak memiliki suatu imajinasi yang hanya } \\
\text { dapat dimengerti oleh dirinya sendiri }\end{array}$ & Autisme \\
\hline 7 & $\begin{array}{l}\text { Jarang menunjukan suatu emosi ketika } \\
\text { bersosialisasi }\end{array}$ & $\begin{array}{l}\text { Adanya intensi tertentu untuk memuaskan } \\
\text { diri }\end{array}$ & Retardasi mental \\
\hline 8 & $\begin{array}{l}\text { Kehilangan minat terhadap sesuatu yang } \\
\text { disukainya? }\end{array}$ & $\begin{array}{l}\text { Adanya rasa kurang percaya diri yang } \\
\text { berlebihan dan kurangnya dukungan orang } \\
\text { terdekat }\end{array}$ & Disleksia \\
\hline 9 & $\begin{array}{l}\text { Ketika di tanyai tentang suatu tempat atau } \\
\text { peristiwa malah mengelak? }\end{array}$ & $\begin{array}{l}\text { Mengalami suatu peristiwa yang susah } \\
\text { untuk dilupakan atau sangat melekat pada } \\
\text { dirinya }\end{array}$ & Adhd \\
\hline 10 & $\begin{array}{l}\text { Merasakan kesenangan yang berlebihan } \\
\text { dengan apa yang dikerjakannya? }\end{array}$ & $\begin{array}{l}\text { Berusaha untuk menutupi peristiwa apa } \\
\text { yang sudah dialaminya }\end{array}$ & Disosiatif \\
\hline 11 & $\begin{array}{l}\text { Musah tersinggung ketika diberikan masukan } \\
\text { terhadap apa yang dikerjakannya? }\end{array}$ & Adanya kejadian buruk menimpanya & \\
\hline 12 & $\begin{array}{l}\text { Perubahan emosi yang sangat derastis karena } \\
\text { mengingat traumanya? }\end{array}$ & $\begin{array}{l}\text { Memiliki kepuasan atas tindakan buruk } \\
\text { yang dillakukannya }\end{array}$ & \\
\hline 13 & $\begin{array}{l}\text { Sering berbohong bahkan mengeksploitasi } \\
\text { orang lain }\end{array}$ & Kurang memiliki rasa kepedulian sosial & \\
\hline 14 & Susah tidur atau insomnia? & $\begin{array}{l}\text { Karena memiliki rasa superior akan suatu } \\
\text { hal atau keadaan }\end{array}$ & \\
\hline 15 & $\begin{array}{l}\text { Tidak adanya rasa bersalah ketika membuat } \\
\text { kesalahan }\end{array}$ & $\begin{array}{l}\text { Kurangnya intensitas komunikasi anak } \\
\text { dengan orang tua }\end{array}$ & \\
\hline 16 & $\begin{array}{l}\text { Tidak bertanggung jawab atas kesalahannya } \\
\text { atau menyalahkan orang lain }\end{array}$ & Adanya disabilitas intelektual pada anak & \\
\hline 17 & $\begin{array}{l}\text { Tidak mampu menahan dorong atas perilaku } \\
\text { tertentu? }\end{array}$ & $\begin{array}{l}\text { Anak memiliki imajinasi berlebih yang } \\
\text { tidak dapat disampaikan }\end{array}$ & \\
\hline 18 & Tidak percaya diri di lingkungan sekitar? & $\begin{array}{l}\text { Karena adanya kelainan kesehatan pada } \\
\text { anak }\end{array}$ & \\
\hline 19 & Anak berperilaku impulsif dan hiperaktif. & $\begin{array}{l}\text { Karena adanya perasaan yang membuat } \\
\text { dirinya merasa tidak dibutuhkan pada } \\
\text { lingkungannya }\end{array}$ & \\
\hline 20 & Apakah anak kesulitan dalam berkomunikasi? & Perkembangan indera yang lamban & \\
\hline 21 & $\begin{array}{l}\text { Apakah anak memliki penyimpangan pada } \\
\text { ingatannya? }\end{array}$ & Adanya gangguan terhadap kerja otak anak & \\
\hline 22 & $\begin{array}{l}\text { Apakah anak mengalami gangguan saat } \\
\text { bersosialisasi? }\end{array}$ & $\begin{array}{l}\text { Karena kepuasan harus dipenuhi dengan } \\
\text { melakukan suatu aktivitas yang } \\
\text { melelahkannya }\end{array}$ & \\
\hline 23 & $\begin{array}{l}\text { Jika disuruh diam akan gelisah, karena anak } \\
\text { selalu ingin bergerak. }\end{array}$ & $\begin{array}{l}\text { Adanya penyimpangan memori pada otak } \\
\text { anak }\end{array}$ & \\
\hline 24 & $\begin{array}{l}\text { Kesulitan dalam mengeja, membaca, menulis, } \\
\text { dan berhitung. }\end{array}$ & $\begin{array}{l}\text { Anak terbiasa menutupi sifat aslinya } \\
\text { dilingkungan sekitar agar terlihat } \\
\text { menyenangkan }\end{array}$ & \\
\hline 25 & $\begin{array}{l}\text { Kesulitan menemukan kata yang tepat untuk } \\
\text { menjawab suatu pertanyaan. }\end{array}$ & & \\
\hline 26 & Kesulitan mengingat huruf, angka, dan warna. & & \\
\hline 27 & $\begin{array}{l}\text { Kesulitan mengucapkan kata yang tidak } \\
\text { umum. }\end{array}$ & & \\
\hline
\end{tabular}




\begin{tabular}{cl}
\hline $\mathbf{2 8}$ & $\begin{array}{l}\text { Ketidakmampuan dalam memahami } \\
\text { konsekuensi terhadap tindakan yang diambil. }\end{array}$ \\
\hline $\mathbf{2 9}$ & Lamban dalam mempelajari hal-hal penting \\
\hline $\mathbf{3 0}$ & Memiliki gangguan psikologis \\
\hline $\mathbf{3 1}$ & $\begin{array}{l}\text { Memliki bahasa atau gerakan tubuh yang } \\
\text { cenderung kaku? }\end{array}$ \\
\hline $\mathbf{3 2}$ & Mengalami gejala depersonalisasi. \\
\hline $\mathbf{3 3}$ & $\begin{array}{l}\text { Penalaran yang buruk dan juga daya ingat } \\
\text { yang buruk }\end{array}$ \\
\hline $\mathbf{3 4}$ & $\begin{array}{l}\text { Sering marah, menangis atau tertawa tanpa } \\
\text { alasan yang kuat? }\end{array}$ \\
\hline $\mathbf{3 5}$ & $\begin{array}{l}\text { Sering melakukan aktivitas yang } \\
\text { membahayakan diri sendiri? }\end{array}$ \\
\hline $\mathbf{3 6}$ & $\begin{array}{l}\text { Sering merasa asing dengan orang sekitar. } \\
\text { S7 }\end{array}$ \\
& $\begin{array}{l}\text { Sulit dalam membedakan huruf tertentu saat } \\
\text { menulis, misalnya 'd' dengan 'b' atau 'm' }\end{array}$ \\
\hline $\mathbf{3 8}$ & \begin{tabular}{l} 
Sulit dalam memusatkan perhatian. \\
\hline
\end{tabular}
\end{tabular}

Tabel 2 adalah data gejala dan faktor yang di tunjukkan oleh anak ketika mereka menderita gangguan psikologis dari beberapa penyakit diatas.

\subsection{Representasi}

Setelah mendapatkan data-data yang diatas, maka data tersebut dimanfaatkan untuk diproses oleh sistem untuk dijadikan sebuah aturan. Aturan tersebut nantinya digunakan untuk mencocokkan gejala apa yang dirasakan dan nantinya akan menghasilkan sebuah pengetahuan untuk para pengguna.

Tabel 3. Data rule

\begin{tabular}{cccc} 
No & Gejala & Penyakit & Faktor \\
\hline 1 & G1,G2,G3,G4 & P1 & F1,F2,F3,F4 \\
\hline 2 & G1,G5,G6,G7 & P2 & F1,F5,F6 \\
\hline 3 & G8,G9,G10 & P3 & F7,F8 \\
\hline 4 & G11,G12,G13,G14 & P4 & F1,F9,F10 \\
\hline 5 & G15,G16,17,G18 & P5 & F11,F12,F13 \\
\hline 6 & G19,G20,G21,G22,G23 & P6 & F14,F15,F16 \\
\hline 7 & G24,G25,G26 & P7 & F117,18 \\
\hline 8 & G27,G28,G29,G30,G31 & P8 & F19,20 \\
\hline 9 & G32,G33,G34 & P9 & F21,F22 \\
\hline 10 & G35,G36,G37,G38 & P10 & F23,F24
\end{tabular}

Keterangan Tabel 3 :

$\mathrm{G}$ : Data gejala pada tabel 2

F : Data faktor pada tabel 2

$\mathrm{P}$ : Data penyakit pada tabel 2 


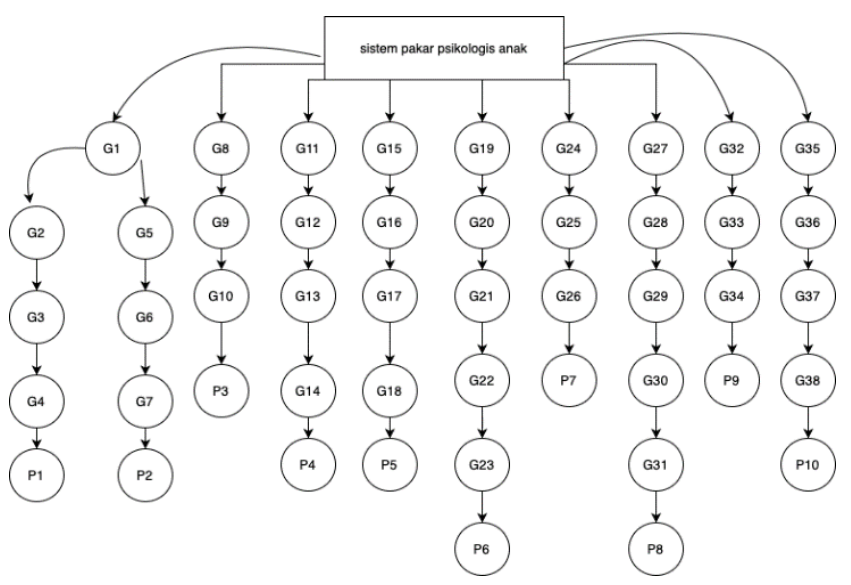

Gambar. 3. Hasil representasi dari data yang dikumpulkan lalu dijadikan sebuah aturan-aturan untuk mendapatkan keputusan layaknya seorang pakar.

\subsection{Perancangan Aplikasi}

Aplikasi ini dibuat berdasarkan dari rancangan yang sudah disiapkan seperti rancangan database, rancangan UML agar aplikasi berjalan sesuai dengan yang diinginkan dan mampu memudahkan user menggunakannya. Berikut hasil dari rancangan tersebut:
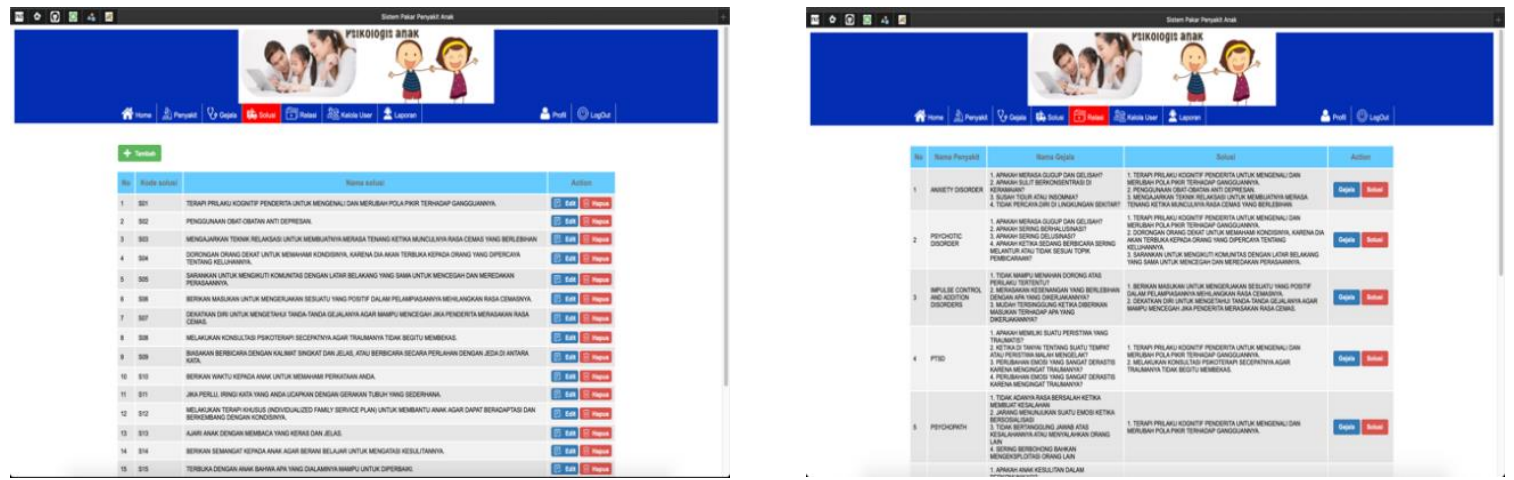

Gambar. 4. Menu diatas hanya mampu diakses oleh admin untuk menambahkan data-data yang digunakan oleh aplikasi sistem pakar.
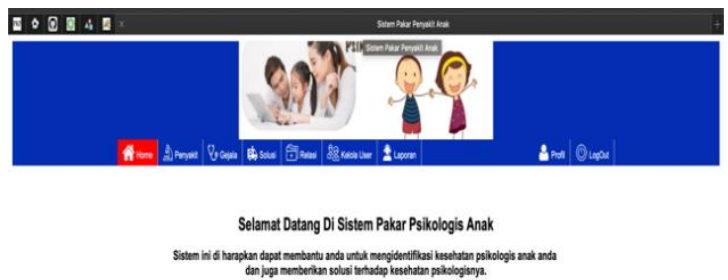

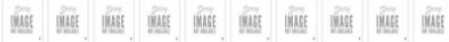

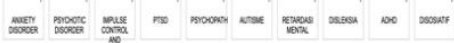

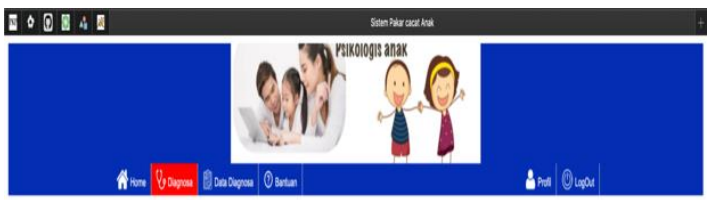

Diagnosa

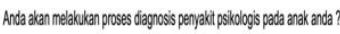

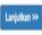

Gambar. 5. Menu diatas menunjukan kepada pengguna penyakit apa saja yang bisa dideteksi oleh aplikasi sistem pakar tersebut. 


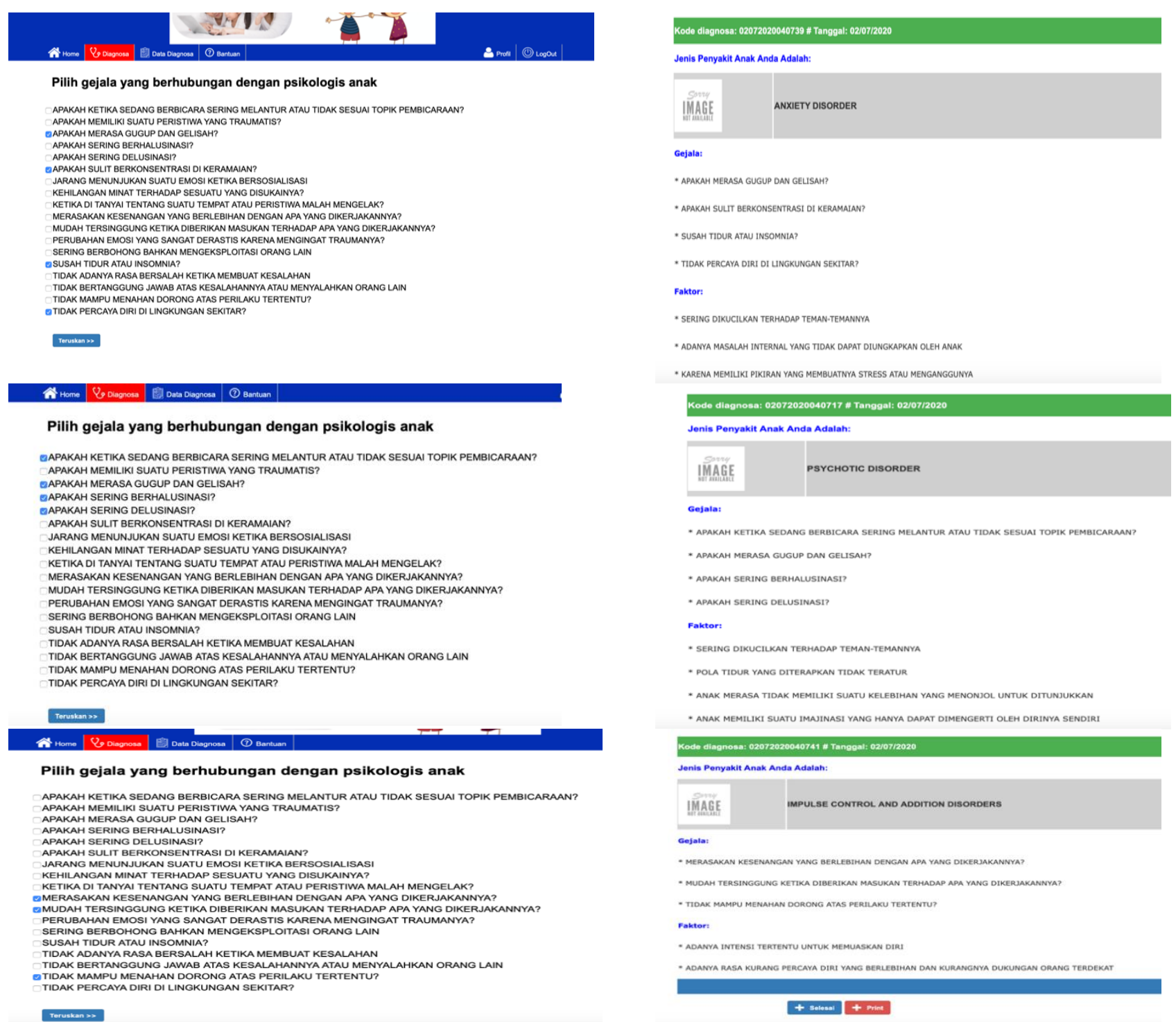

Gambar. 6. Pengujian aplikasi sistem pakar untuk melihat apakah memberikan hasil yang sesuai dengan rules yang sudah disusun dari data yang didapatkan.

\subsection{Pengujian Aplikasi}

Pengujian aplikasi dilakukan untuk mendapatkan persentase ketepatan dalam proses pengklasifikasian data testing yang di uji.

Rumus menghitung akurasi : Akurasi $=\frac{\sum \text { match }}{\sum t p}$

$\sum$ match : total pengujian yang cocok

$\sum$ tp : total pengujian

Tabel 4. Hasil pengujian aplikasi

\begin{tabular}{cccc}
\hline No & Diagnosa Pakar & Diagnosa aplikasi & Nilai \\
\hline 1 & Autism & Autism & 1 \\
\hline 2 & Autism & Autism & 1 \\
\hline 3 & Retardasi mental & Retardasi mental & 1 \\
\hline
\end{tabular}




\begin{tabular}{lccc}
\hline 4 & Retardasi mental & Retardasi mental & 1 \\
\hline 5 & Diseleksia & Diseleksia & 1 \\
\hline 6 & Diseleksia & Diseleksia & 1 \\
\hline 7 & ADHD & ADHD & 1 \\
\hline 8 & PTSD & Pyscopath & 0 \\
\hline 9 & Autism & Autism & 1 \\
\hline
\end{tabular}

Nilai akurasi $=\frac{8}{9} \times 100 \%$

Jadi dapat disimpulkan bahwa akurasi sistem pakar berdasarkan 9 data yang diuji adalah $88 \%$ yang menunjukkan bahwa sistem pakar ini berfungsi cukup baik.

\section{Kesimpulan}

Berdasarkan hasil dari pembuatan sistem pakar konsultasi psikologis anak, dapat disimpulkan sebagai berikut :

1. Sistem pakar ini memberikan informasi penyakit yang di derita oleh anak dan solusi awal untuk menanganinya.

2. Aplikasi sistem pakar berfungsi mendeteksi penyakit psikologis anak menggunakan metode forward chining dari gejala yang dialami oleh sang anak.

3. Berdasrkan hasil pengujian aplikasi sistem pakar, didapatkan hasil persentase sebesar $88 \%$ yang menunjukkan bahwa aplikasi berfungsi cukup baik dan mampu meningkatkan efektifitas konsultasi.

4. Pengujian rules yang dihasilkan sesuai dengan data representasi yang sudah dibuat yang didapatkan melalui pakar setelah melakukan beberapa revisi.

\section{Referensi}

[1] Mussen, Paul, Psychology an introduction. Lexington, D.C. Heat and Co, 1973.

[2] A. Andriani, Pemrograman Sistem Pakar. Yogyakarta: MediaKom, 2017.

[3] D. Muhammad, S. Rosindah, and Dkk, “PENGERTIAN SISTEM PAKAR,” J. Chem. Inf. Model., 2013.

[4] J. Giarattano and G. Riley, Expert System Principles and Programming. Boston: PWS Publising Company, 1994.

[5] Kusumadewi, Sri, Artifical Intelligence ( Teknik dan Aplikasinya ). Yogyakarta, 2003.

[6] dr. I Nyoman Budastra, Sp.A 